\title{
Design Aspects and Test of an Inductive Fault Current Limiter
}

\author{
Pedro Arsénio (PhD Student, Nova University of Lisbon), Nuno Vilhena (PhD Student, Nova University of Lisbon), \\ João Murta-Pina (Professor, Nova University of Lisbon), Anabela Pronto (Professor, Nova University of Lisbon), \\ Alfredo Álvarez (Professor, University of Extremadura)
}

\begin{abstract}
Magnetic shielding inductive fault current limiters with high temperature superconducting tapes are considered as emerging devices that provide technology for the advent of modern power grids. The development of such limiters requires magnetic iron cores and leads to several design challenges regarding the constitutive parts of the limiter, namely the primary and secondary windings. Preliminary tests in a laboratory scale prototype have been carried out considering an assembly designed for simplicity in which the optimization of the magnetic coupling between the primary and secondary was not the main focus. This work addresses the design configuration of an inductive current limiter prototype regarding the assembly of the primary and secondary windings in the core. The prototype is based on a closed magnetic core wound by a primary, built from a normal electric conductor, and a short-circuited secondary, built from first generation superconducting tape. Four different design configurations are considered. Through experimental tests, the performance of such prototype is discussed and compared, in terms of normal and fault operation regimes. The results show that all the configurations assure effective magnetic shielding at normal operation regime, however, at fault operation regime, there are differences among configurations.
\end{abstract}

Keywords - Fault current limiters; High-temperature superconductors; Power grids; Short-circuit currents.

\section{INTRODUCTION}

Electric power equipment has to be designed to maintain modern power networks highly reliable and fail-safe in order to contribute to saving costs and operational optimization. It is common oversizing some electric power equipment in order to deal with faults such as short-circuit currents the values of which may highly exceed the nominal values. However, oversizing the majority of the electric power equipment tends to be very expensive that leads to becoming unfeasible. For these reasons, there are several current limiting devices that help to reduce the costs of investment on oversized power equipment. Nevertheless, it is not enough to limit the current. Features such as very rapid reaction, self-reset after a fault and minimal impact on the grid performance are other desired features [1], [2], [3] and [4].

Superconducting fault current limiters (SFCLs) are considered as emerging devices that provide technology for the advent of modern electricity networks and thus helping to mitigate several operation problems that such grids can experience as well as prevent the upgrade of the equipment [5] and [6].

Among all different topologies of SFCLs, the resistive is the one that has been most developed and subjected in many field tests, see e.g. [7], [8] and [9]. This topology uses a high temperature superconductor (HTS) material that is in series with the line circuit and uses the transition from the superconducting state to normal state to limit short circuit currents. The design is very compact; however the need for current results in losses even during normal operation. On the other hand, inductive SFCLs require an iron core which make them relatively heavy but do not need current leads, require lesser amounts of superconductor and are robust against hotspot formation. A field test has carried out by ABB Company many years ago using HTS bulk cylinders [10], and only recently, due to the emergence of HTS tapes [11], [12], [13] and [14], several projects have been performed, either using first generation [15] or second generation tapes [16].

This work addresses the design issues of a magnetic shielding inductive SFCL prototype and presents experimental results of normal and fault current regimes in order to understand performance dissimilarities between the different assemblies that were carried out. These experiments are important in order to understand the design challenges that are involved and provide pertinent information for the development of a medium voltage device.

\section{A. Research Question}

The collected information of this work will contribute to answer the ongoing research question:

Taking into account modern power grids, based on dispersed, embedded or distributed generation, are inductive SFCLs attractive devices in terms of performance to protect such grids from short-circuit faults?

\section{B. Motivation}

The motivation behind this research lies on the recent developments of high quality HTS materials that can provide the development of several applications, such as SFCLs, without any counterpart on conventional electric power equipment, which might help to solve several problems that surge from the emergence of modern power grids [17].

The growing demand for energy provided from distributed generation, mostly from renewable energy sources, requires optimized, controlled and secure connections to electric transmission and distribution grids. Since most of distributed generators are under environmental phenomena dependency, their amount of generated energy is variable as function of time and environmental conditions, which means that such grids are inherent fault-susceptible due to unpredicted current flows [18]. For these reasons, fault current limiters are used to 
prevent short-circuit damages and avoid expensive upgrading of the grid.

Fault operation regimes, such as short-circuit currents, can compromise the security, reliability, and availability of the electric equipment present in the grid [19]. In order to avoid chaotic occurrences and provide reliability to energy delivery, contributing to the increased penetration of renewable energy sources in modern power grids, SFCLs have been found, see e.g. [7], [8] and [10] that have potential to perform an enhancement of energy management systems by assuming a collaborative behavior through the limitation of short-circuit currents that are the result of their awareness of fault operation regimes in the grid. The SFCLs offers very close characteristics to the ideal fault current limiter [5] and [20].

\section{II.PROTOTYPE AND EXPERIMENTAL APPARATUS}

Magnetic shielding SFCLs are based on the same principle of the transformer but with the secondary shorted. The magnetic core of the developed prototype is wound by a primary coil, built from a normal electric conductor, and a short-circuited secondary coil, built from the first generation superconducting tape. The primary is connected in series to the circuit under protection.

During normal operation regime, the short-circuited secondary shields magnetically the core ensuring negligible voltage drop at the terminals of the primary, since no magnetic flux flows in the magnetic core. When a fault occurs, the line current increases abruptly which induces high currents in the secondary and thus quenching the HTS material. As a consequence, the impedance of the primary coil increases due to the penetration of magnetic flux in the core. For these reasons, the limiter autonomously triggers itself. When the fault is suppressed, the limiter recovers its original state almost instantaneously [21] and [22].

Ideally, this device ensures negligible voltage drop at its terminals during normal operation regime and effective current limitation in fault operation regimes. The instantaneous and autonomous time response to fault events and its capability to recover after fault clearances, makes this kind of SFCL an attractive device to protect electric power grids [23], [24] and [25].

Due to assembly simplicity, a previous work [6] has considered the primary and secondary of the limiter placed on different core limbs. Nevertheless, there is a likelihood of such assembly to be not fully optimized in terms of performance. The performance can be evaluated by the voltage drop over the primary coil terminals of the limiter as function of the line current and linked flux, which is expressed analytically as

$$
u(t)=\mathrm{r} \cdot i(t)+\frac{d \psi(t)}{d t} .
$$

Where $\mathrm{u}, \mathrm{r}$, and $\mathrm{i}$ are, respectively, the voltage drop, resistance and current of the primary, and $\psi$ is its linked flux. It is considered that the resistance of the primary remains nearly constant over time $t$.
TABLE I

CHARACTERISTICS OF THE PRIMARY OF THE LiMITER

\begin{tabular}{|l|l|}
\hline Material & Copper \\
\hline Number of turns & 20,60 or 80 \\
\hline Inner radius & $32 \mathrm{~mm}$ \\
\hline Width & $45 \mathrm{~mm}$ \\
\hline Cross section of conductor & $1.5 \mathrm{~mm}^{2}$ \\
\hline
\end{tabular}

TABLE II

CHARACTERISTICS OF THE SECONDARY OF THE LIMITER

\begin{tabular}{|l|l|}
\hline Material & HTS Bi-2223 \\
\hline Supplier & Innost \\
\hline Reference & Bi-2223 insulated \\
\hline Inner radius of rings & $41 \mathrm{~mm}$ \\
\hline Tape width & $4.2 \mathrm{~mm}$ \\
\hline Tape thickness & $0.23 \mathrm{~mm}$ \\
\hline Critical current at $77 \mathrm{~K}$ & $90 \mathrm{~A}$ \\
\hline
\end{tabular}
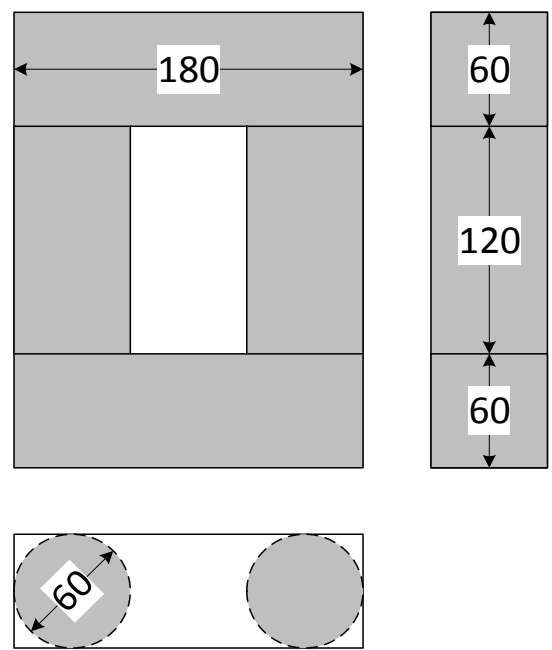

Fig. 1. Dimensions (in millimeters) of the magnetic core used to perform the limiter.

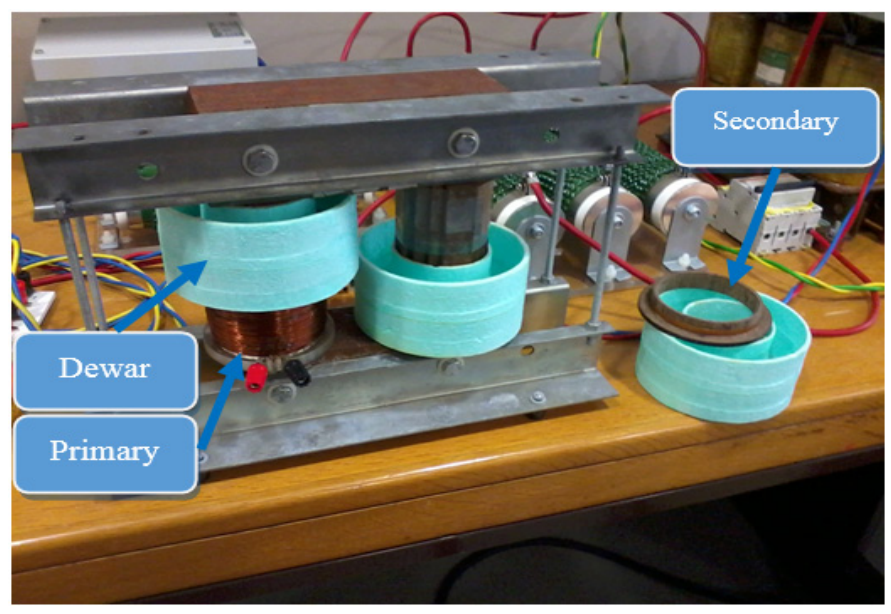

Fig. 2. SFCL prototype with primary and secondary. The primary is wrapped around an acrylic holder, while the secondary is wrapped around a Celeron holder and placed inside a Dewar. 


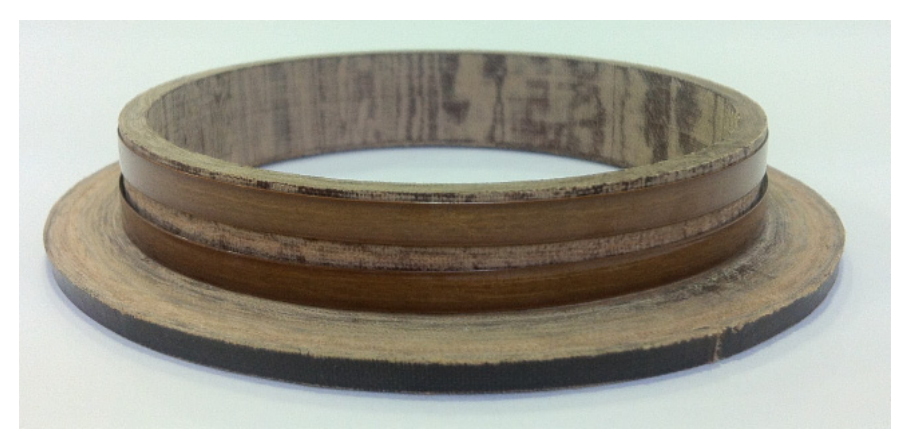

Fig. 3. View of the secondary, built by two first generation superconducting tapes wrapped around a Celeron holder.

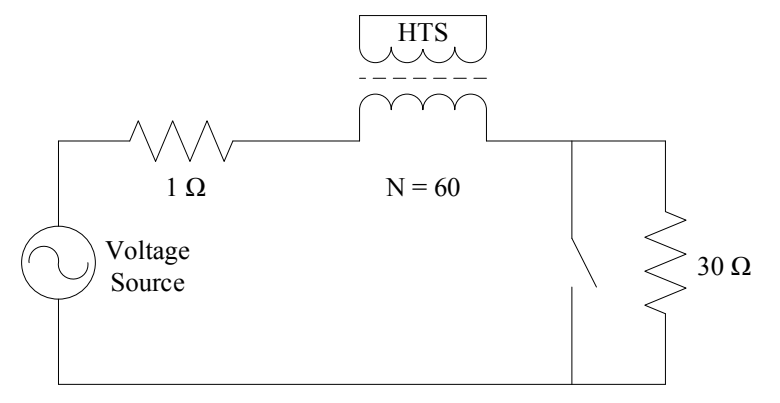

Fig. 4. Diagram of the test circuit. Short-circuit faults are intentionally induced by nulling the load, which is carried out by closing the circuit-breaker.

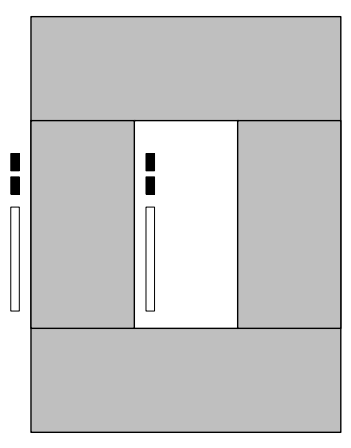

(a)

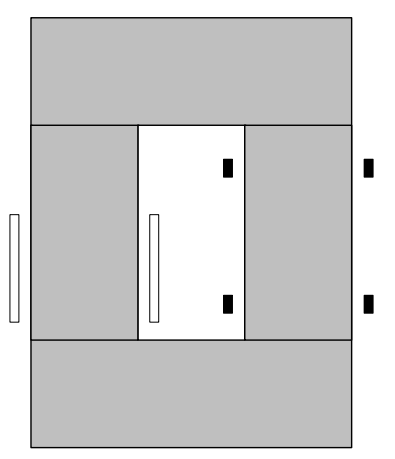

(c)

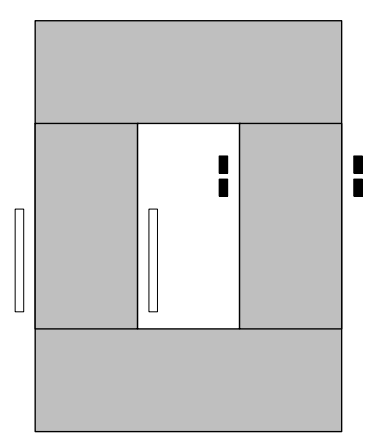

(b)

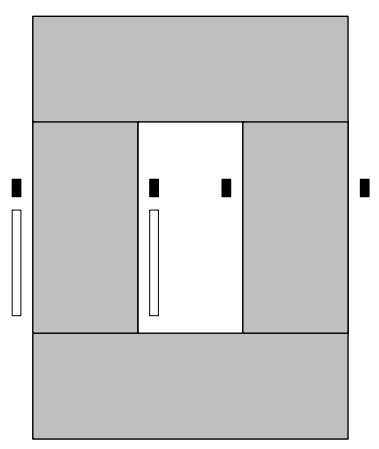

(d)
Fig. 5. Different configurations of the SFCL. The primary and secondary coils are painted with white and black background, respectively. Dewars are used to keep superconducting coils below their critical temperature. (a) Configuration A. (b) Configuration B. (c) Configuration C. (d) Configuration D.
The SFCL prototype is built considering a two-legged magnetic core, whose dimensions are depicted in Fig. 1. The developed prototype is shown in Fig. 2, in which the primary with 60 turns and a secondary (placed inside Dewars with liquid nitrogen) with one or two HTS rings of Bi-2223 are chosen, being shown in Fig. 3. The characteristics of the primary and secondary are presented in Tables I and II, respectively.

\section{EXPERIMENTAL RESULTS AND DISCUSSION}

The experimental results were carried out on the developed prototype by means a test circuit as depicted in Fig. 4. The current in the circuit, the voltage drop over the terminals of the primary as well as its linked flux were measured. The measurement of the linked flux with the primary is carried out by integrating the voltage drop over the terminals of an auxiliary coil. In order to evaluate the current limitation, prospective currents are also computed by measuring the voltage provided from the source and the impedance of the circuit. The measurements were made with National Instruments NI-6009 data acquisition board and afterward processed in LabView Signal Express and Microsoft Excel.

The experimental setup is based on an $80 \mathrm{~V}$ voltage source feeding a $30 \Omega$ load and a circuit-breaker which is used to intentionally introduce faults in the circuit in order to observe the performance of the limiter. The $1 \Omega$ resistance is used to provide an image of the current in the circuit by measuring its voltage drop.

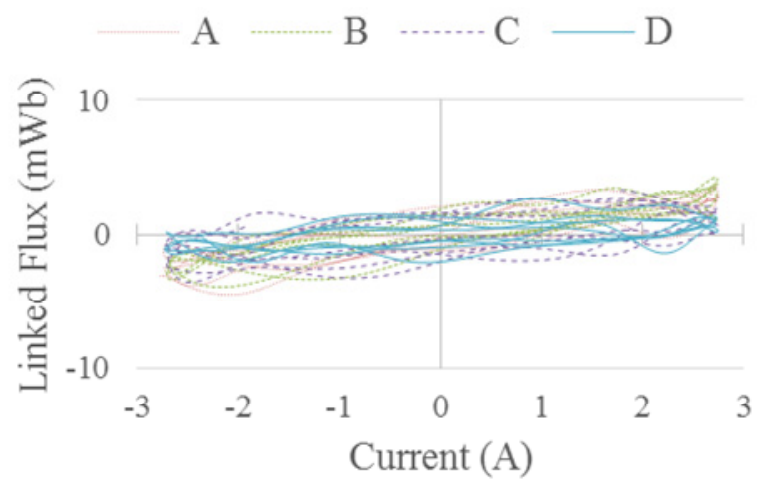

Fig. 6. Characteristic of the linked flux as function of line current during the normal operation regime.

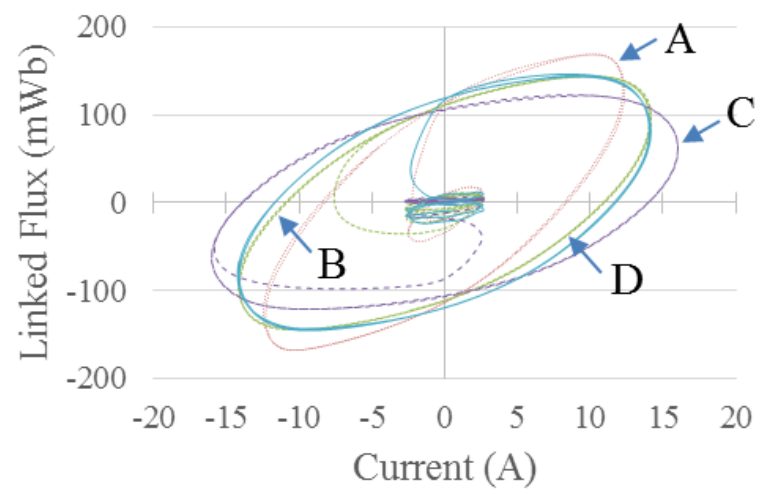

Fig. 7. Characteristic of the linked flux as function of line current during the transition from fault operation regime to normal operation regime. 


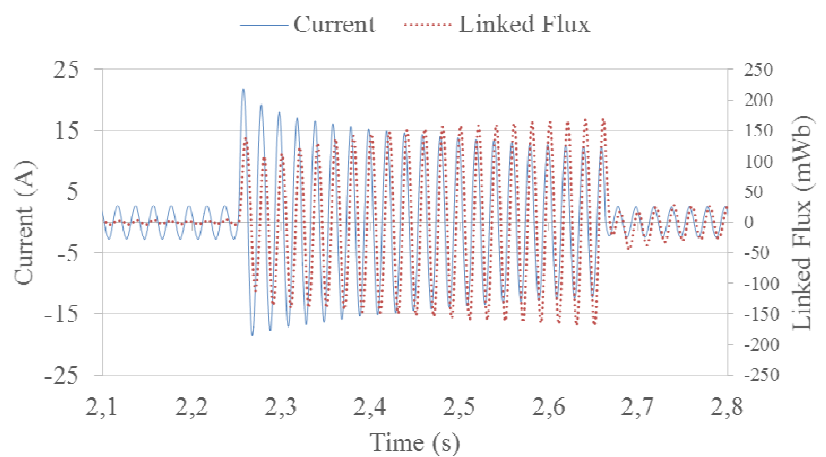

Fig. 8. Fault current limitation performance for prospective currents of $80 \mathrm{~A}$ regarding configuration $\mathrm{A}$.

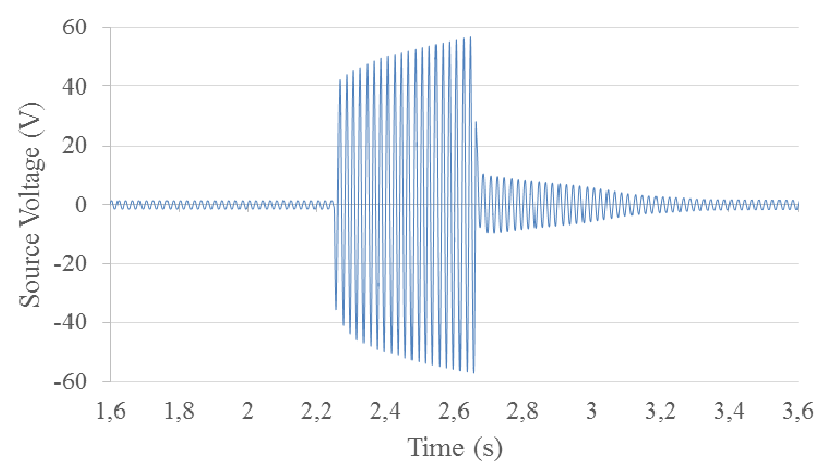

Fig. 9. Voltage drop over the terminals of the limiter for prospective currents of 80 A regarding configuration $\mathrm{A}$.

TABLE III

MAXimum Measured VALUES At NORMAL Operation Regime

\begin{tabular}{|c|c|c|}
\hline Configuration & Current (A) & Linked Flux (mWb) \\
\hline A & 2.8 & 4.6 \\
\hline B & 2.7 & 5.2 \\
\hline C & 2.7 & 3.6 \\
\hline D & 2.7 & 2.9 \\
\hline
\end{tabular}

TABLE IV

MaXimum MEASUREd VALUES AT FAULt OPERATION REgIME

\begin{tabular}{|c|c|c|}
\hline Configuration & Current (A) & Linked Flux (mWb) \\
\hline A & 12.4 & 169.1 \\
\hline B & 14.2 & 143.7 \\
\hline C & 16.0 & 122.5 \\
\hline D & 14.2 & 146.4 \\
\hline
\end{tabular}

TABLE V

MaXimum Measured VALues for Time Response of Configuration A

\begin{tabular}{|c|c|}
\hline \multicolumn{2}{|c|}{ Normal Operation } \\
\hline Current (A) & 12.4 \\
\hline Linked Flux (mWb) & 4.6 \\
\hline \multicolumn{2}{|l|}{ Fault Operation } \\
\hline Peak Current (A) & 21.9 \\
\hline Prospective Current (A) & 80.0 \\
\hline Linked Flux (mWb) & 169.1 \\
\hline
\end{tabular}

Four different configurations of the SFCL were performed, as it can be seen illustrated in Fig. 5. In each configuration, the primary keeps fixed whereas the secondary and dewars are placed on the magnetic core according to the following design criteria:

- Configuration A: Two HTS rings close from each other placed on the same limb of the primary. One dewar is used.

- Configuration B: Two HTS rings close from each other placed on the opposite limb of the primary. One dewar is used.

- Configuration C: Two HTS rings far from each other placed on the opposite limb of the primary. Two dewars are used.

- Configuration D: One HTS ring on each limb. Two dewars are used.

\section{A. Normal Operation Regime}

At normal operation regime is intended negligible voltage drop over the terminals of the limiter, which means that (1) should be as minimum as possible. Since the voltage drop due to ohmic resistance of the primary remains nearly constant in each experiment, it is important to analyse the part that is due to linked flux variances. This part is related to the magnetic shielding performed by the secondary.

The characteristic of the linked flux as a function of line current is illustrated in Fig. 6. The characteristics of all configurations show low flux variance without major differences, which means that each configuration performs effective magnetic shielding, minimizing the penetration of magnetic flux in the core and thus low voltage drop at the terminals of the limiter.

The maximum measured values regarding each configuration are presented in Table III. The maximum values of the current are nearly identical on each configuration and there are no major differences in the maximum values of linked flux.

\section{B. Fault Operation Regime}

At fault operation regime, high current limitation capability is desired, meaning that the SFCL must add high impedance to the circuit, through the loss of magnetic shielding, in order to limit the current. This feature is achieved since there is magnetic flux variance in the magnetic core of the limiter prototype due to the transition of the superconducting tape to the resistive state. This transition is dependent of the magnetomotive force in the primary [3] and [26].

The excursion of the linked flux with the primary as function of line current from a transition between the fault operation and normal operation is depicted in Fig. 7 and it is possible to observe that the configuration A presents the better performance since lower current and high linked flux magnitudes are achieved. Configurations B and D have a very similar excursion and, the configuration $\mathrm{C}$, is the one that present worst performance.

The maximum measured values regarding each configuration are presented in Table IV. As it is observed by the hysteresis loops, the best performance is achieved by the configuration $\mathrm{A}$, where the current was limited to $12.4 \mathrm{~A}$, and 
consequently the linked flux is the highest of all configurations, $169.1 \mathrm{mWb}$. The configurations B and D show quite similar results between each other and the configuration $\mathrm{C}$ presents worst results, allowing to conclude that splitting the secondary does not constitute any advantage, even leading to a more complex design of the device.

\section{Time Response of the Limiter}

The time response performance of the limiter (on its configuration A) under a transition between the normal operation and fault occurrence and vice-versa is shown in Fig. 8, where the limited current and linked flux are depicted. A prospective current of $80 \mathrm{~A}$ is limited to $21.9 \mathrm{~A}$ in the first peak and previously to $13.1 \mathrm{~A}$. The amplitude of the linked flux, at fault operation regime is growing continuously with time, enabling growing current limitation. After the fault suppression, the limiter re-establishes its normal operation principle in less than one second, as it can be seen in Fig. 9.

Table $\mathrm{V}$ presents the maximum measured values. Considering the prospective current and the limited peak current it is found that the prototype, on its best configuration (configuration A), allows to achieve at least $72.6 \%$ of current limitation.

The reduced recovery time after a fault clearance constitutes a great advantage when compared to resistive type limiters [27] and [28].

\section{CONCLUSIONS AND FURTHER WORK}

The growing demand for power provided from distributed generation, mostly from renewable energy sources, requires optimized, controlled and secure connections to distribution electric grids in order to deal with the variable energy production paradigm. SFCLs help to reduce short-circuit current levels in power grids, which allow to avoid their upgrading.

In this paper, the design and test of a magnetic shielding superconducting fault current limiter was described. This study concludes that, at a normal operation regime, all the configurations assure effective magnetic shielding, however the configuration which has the secondary placed on the same limb as the primary (configuration A) provides better current limitation during fault operation. From the experimental tests, this configuration showed prospective currents of 80 A limited to $21.9 \mathrm{~A}$ in the first peak and previously to $13.1 \mathrm{~A}$. Splitting the secondary does not constitute any advantage, it even leads to a more complex design and worst performance in terms of current limitation is achieved.

The design of a prototype in which primary and secondary are placed concentrically constitutes a design challenge but needs to be conducted in the future to evaluate and compare with the configurations considered in this work. Also as the further work, the measuring of the induced currents in the HTS tapes is important in order to detect hot-spot formation during quench of the HTS tapes.

\section{ACKNOWLEDGEMENT}

This work was supported by Fundação para a Ciência e a Tecnologia (Centre of Technology and Systems multiannual funding) under the framework of project Pest-OE/EEI/UI0066/2011 and doctoral fellowships SFRH/BD/85122/2012 and SFRH/BD/92010/2012.

\section{REFERENCES}

[1] S. S. Kalsi, Applications of High Temperature Superconductors to Electric Power Equipment, 1st ed. John Wiley \& Sons, Inc., 2011, p. 333 .

[2] A. Hobl, W. Goldacker, B. Dutoit, L. Martini, A. Petermann, and P. Tixador, "Design and Production of the ECCOFLOW Resistive Fault Current Limiter," IEEE Transactions on Applied Superconductivity, vol. 23, no. 3, pp. 5601804-5601804, Jun. 2013.

[3] J. M. Pina, P. Pereira, A. Pronto, P. Arsénio, and T. Silva, "Modelling and Simulation of Inductive Fault Current Limiters," Physics Procedia, vol. 36, pp. 1248-1253, 2012.

[4] P. Tixador, P, "Development of superconducting power devices in Europe," Physica C: Superconductivity, vol. 470, no. 20, pp. 971-979, Jun. 2010.

[5] H. Heydari, A. A. Abrishami, and M. Mordadi Bidgoli, "Comprehensive Analysis for Magnetic Shield Superconducting Fault Current Limiters," IEEE Transactions on Applied Superconductivity, vol. 23, no. 5, pp. 5604610-5604610, Oct. 2013.

[6] W.-S. Moon, J.-N. Won, J.-S. Huh, and J.-C. Kim, "A Study on the Application of a Superconducting Fault Current Limiter for Energy Storage Protection in a Power Distribution System," IEEE Transactions on Applied Superconductivity, vol. 23, no. 3, pp. 5603404-5603404, Jun. 2013.

[7] A. Hobl, W. Goldacker, B. Dutoit, L. Martini, A. Petermann, and P. Tixador, "Design and Production of the ECCOFLOW Resistive Fault Current Limiter," IEEE Transactions on Applied Superconductivity, vol. 23, no. 3, pp. 5601804-5601804, Jun. 2013.

[8] L. Martini, M. Bocchi, M. Ascade, A. Valzasina, V. Rossi, C. Ravetta, and G. Angeli, "Live-Grid Installation and Field Testing of the First Italian Superconducting Fault Current Limiter," IEEE Transactions on Applied Superconductivity, vol. 23, no. 3, pp. 5602504-5602504, Jun. 2013.

[9] R. Dommerque, S. Krämer, A. Hobl, R. Böhm, M. Bludau, J. Bock, D. Klaus, H. Piereder, A. Wilson, T Krüger, G Pfeiffer, K Pfeiffer, and S. Elschner, "First commercial medium voltage superconducting faultcurrent limiters: production, test and installation," Superconductor Science and Technology, vol. 23, no. 3, pp. 034020, Feb. 2010.

[10] W. Paul, M. Lakner, J. Rhyner, P. Unternährer, T. Baumann, M. Chen, L. Widenhorn, and A. Guérig, "Test of 1.2 MVA high- superconducting fault current limiter," Supercond. Sci. Technol., vol. 10, no. 12, pp. 914 918, Dec. 1997.

[11] C. Y. Shigue, T. T. da Cruz, J. S. Lamas, C. A. Baldan, and E. R. Filho, "Analysis of the E-J Curve of HTS Tapes Under DC and AC Magnetic Fields at $77 \mathrm{~K}$," IEEE Transactions on Applied Superconductivity, vol. 19, no, 3, pp. 3332-3335, Jun. 2009.

[12] J. S. Lamas, C. Baldan, C. Y. Shigue, A. Silhanek, A., and V. Moshchalkov, "Electrical and Magnetic Characterization of BSCCO and YBCO HTS Tapes for Fault Current Limiter Application," IEEE Transactions on Applied Superconductivity, vol. 21, no. 3, pp. 3398-3402, Jun. 2011.

[13] J. C. Llambes, D. Hazelton, J. Duval, M. Albertini, S. Repnoy, V Selvamanickam, G. Majkic, I. Kesign, J. Langston, M. Steurer, F. Bogdan, J. Hauer, D. Crook, S. Ranner, T. Williams, and M. Coleman, "Performance of 2G HTS Tapes in Sub-Cooled LN2 for Superconducting Fault Current Limiting Applications," IEEE Transactions on Applied Superconductivity, vol. 21, no.3, pp. 1206-1208, Jun. 2011.

[14] Y. Shiohara, M. Yoshizumi, Y. Takagi, and T. Izumi, "Future prospects of high Tc superconductors-coated conductors and their applications," Physica C: Superconductivity, vol. 484, pp. 1-5, Mar. 2012. 
[15] P. Arsénio, T. Silva, N. Vilhena, J. M. Pina, and A. Pronto, "Analysis of Characteristic Hysteresis Loops of Magnetic Shielding Inductive Fault Current Limiters," IEEE Transactions on Applied Superconductivity, vol. 23, no. 3, pp. 5601004-5601004, Jun. 2013.

[16] A. Usoskin, F. Mumford, R. Dietrich, A. Handaze, B. Prause, A. Rutt, and K. Schlenga, "Inductive Fault Current Limiters: Kinetics of Quenching and Recovery," IEEE Transactions on Applied Superconductivity, vol. 19, no. 3, pp. 1859-1862, Jun. 2009.

[17] J. M. Pina, M. V. Neves, and A. L. Rodrigues, "High Temperature Superconducting Fault Current Limiters as Enabling Technology in Electrical Grids with Increased Distributed Generation Penetration," First IFIP WG 5.5/SOCOLNET Doctoral Conference on Computing, Electrical and Industrial Systems, vol. 314, pp. 427- 434, 2010.

[18] C. Gandioli, M. Alvarez-Herault, P. Tixador, N. Hadjsaid, and D.-M. R. Medina, "Innovative Distribution Networks Planning Integrating Superconducting Fault Current Limiters," IEEE Transactions on Applied Superconductivity, vol. 23, no. 3, pp. 5603904-5603904, Jun. 2013.

[19] Y. Shiohara, M. Yoshizumi, Y. Takagi, and T. Izumi, "Future prospects of high Tc superconductors-coated conductors and their applications," Phys. C Supercond., vol. 484, pp. 1-5, Jan. 2013.

[20] Heydari, H., Faghihi, F., Sharifi, R., and Poursoltanmohammadi, A. H., "Superconducting technology for overcurrent limiting in a $25 \mathrm{kA}$ current injection system," Superconductor Science and Technology, vol. 21, no. 9, pp. 095016, Jul. 2008.

[21] A. Usoskin, F. Mumford, R. Dietrich, A. Handaze, B. Prause, A. Rutt, and K. Schlenga, "Inductive Fault Current Limiters: Kinetics of Quenching and Recovery," IEEE Transactions on Applied Superconductivity, vol. 19, no. 3, pp. 1859-1862, Jun. 2009.

[22] M. Noe, and M. Steurer, "High-temperature superconductor fault current limiters: concepts, applications, and development status," Superconductor Science and Technology, vol. 20, no. 3, R15-R29, Jan. 2007.

[23] S. Kozak, T. Janowski, G. Wojtasiewicz, J. Kozak, B. Kondratowicz-Kucewicz, and M. Majka, "The $15 \mathrm{kV}$ Class Inductive SFCL," IEEE Transactions on Applied Superconductivity, vol. 20, no. 3, pp. 1203-1206, Jun. 2010.

[24] J. Kozak, M. Majka, S. Kozak, and T. Janowski, "Design and Tests of Coreless Inductive Superconducting Fault Current Limiter," IEEE Transactions on Applied Superconductivity, vol. 22, no. 3, pp. 5601804-5601804, Jun. 2012.

[25] G. Wojtasiewicz, T. Janowski, S. Kozak, J. Kozak, M. Majka, and B. Kondratowicz-Kucewicz, "Experimental Investigation of a Model of a Transformer-Type Superconducting Fault Current Limiter With a Superconducting Coil Made of a 2G HTS Tape," IEEE Transactions on Applied Superconductivity, vol. 24, no. 3, pp. 1-5, Jun. 2014.

[26] V. Meerovich, V. Sokolovsky, and I. Vajda, "Calculation principles for a superconducting current-limiting transformer," Superconductor Science and Technology, vol. 20, no. 10, pp. 1046-1053, 2007.

[27] Y. Shirai, K. Fujikawa, T. Kitagawa, M. Shiotsu, H. Hatta, S. Muroya, and T. Nitta, "Study on recovery time of a superconducting fault current limiter with adjustable trigger current level," IEEE Transactions on Applied Superconductivity, vol. 11, no. 1, pp. 2086-2089, Mar. 2001

[28] J. Kozak, M. Majka, S. Kozak, and T. Janowski, "Comparison of Inductive and Resistive SFCL," IEEE Transactions on Applied Superconductivity, vol. 23, no. 3, pp. 5600604-5600604, Jun. 2013.

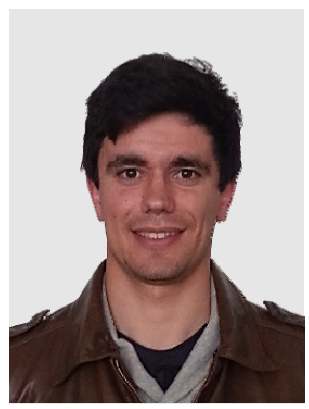

Pedro Arsénio received the M.Sc. degree in Electrical and Computer Engineering from Faculty of Sciences and Technology of Nova University of Lisbon, Portugal, in 2012.

$\mathrm{He}$ is currently pursuing the Ph.D. degree in the Energy Efficiency Research Group at Uninova - Centre of Technology and Systems, Nova University of Lisbon. His research interests include superconducting fault current limiters, joining of superconducting coated conductors, power transformers as well as modelling and simulation of power systems.

$\mathrm{He}$ is a student member of IEEE and

Portuguese Engineers board

Postal address: Centre of Technology and Systems (CTS-UNINOVA), Campus da Faculdade de Ciências e Tecnologia, Monte de Caparica, 2829-516 Caparica, Portugal. E-mail: p.arsenio@campus.fct.unl.pt.

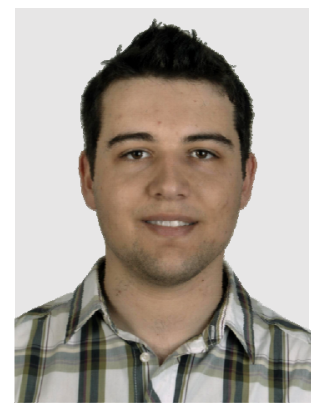

Nuno Vilhena received his M.Sc degree in Electrical Engineering, from Faculty of Sciences and Technology of Nova University of Lisbon, Lisbon, Portugal, in 2012. He is currently working as a researcher in CTS-UNINOVA and he is a candidate of $\mathrm{PhD}$ degree at the same university. His research interests include superconducting fault current limiters, modelling and simulation of power systems and power transformers.

$\mathrm{He}$ is a IEEE student member and a Portuguese Engineers Association student member.

Postal address: Centre of Technology and Systems (CTS-UNINOVA), Campus da Faculdade de Ciências e Tecnologia, Monte de Caparica, 2829516 Caparica, Portugal. E-mail: n.vilhena@campus.fct.unl.pt.

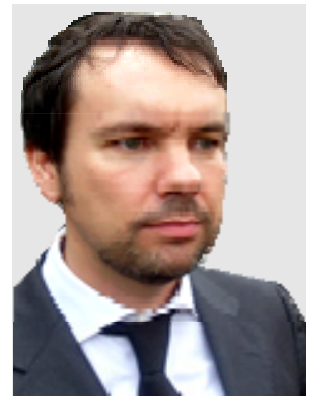

João Murta-Pina has received 5 year diploma, MSc and $\mathrm{PhD}$ in electrical engineering in 1995, 2002 and 2010.

$\mathrm{He}$ has worked on applications of artificial intelligence to industrial processes in $\mathrm{IN}+$ Center for Innovation, Technology and Policy Research from Instituto Superior Técnico, Lisbon, Portugal, and, since 2000, his research has been focused on power applications of high temperature superconducting materials, renewable energy and special electrical drives.

$\mathrm{He}$ is a member of IEEE and Portuguese Engineers Board.

Postal address: Centre of Technology and Systems (CTS-UNINOVA), Campus da Faculdade de Ciências e Tecnologia, Monte de Caparica, 2829-516 Caparica, Portugal. E-mail: jmmp@fct.unl.pt.

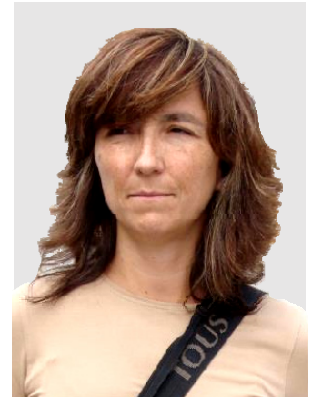

Anabela Pronto received the Dipl. Eng. Degree in Materials Engineering from Faculty of Sciences and Technology (FCT) of New University of Lisbon, in 1992. In 1996, she began her career in Electrical Department of FCT, as a lecturer, in the area of energy and electrical machines. At 2010, she received her $\mathrm{PhD}$ degree in energy field.

Jointly with teaching and research work in energy field, from 1994 to 2003 she also participated in European Union projects, through FCT, in the field of systems of energy production and conversion, and their social, environmental and economic implications. A great number of these projects are concerning developing countries. Now she is professor at FCT Electrical Engineering Department and is involved in teaching and research activities in the field of electrical machines, energy materials technology and applied superconductivity, namely in superconducting power transformers.

Postal address: Centre of Technology and Systems (CTS-UNINOVA), Campus da Faculdade de Ciências e Tecnologia, Monte de Caparica, 2829-516 Caparica, Portugal. E-mail: amg1@fct.unl.pt.

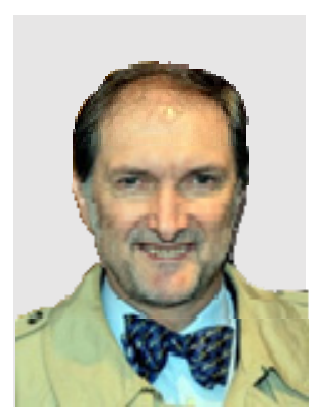

the head of.

Postal address: "Benito Mahedero" Group of Electrical Applications of Superconductors, Escuela de Ingenierías Industriales, Universidad de Extremadura, Avenida de Elvas s/n, 06006 Badajoz, Spain. E-mail: aalvarez@unex.es.
Alfredo Álvarez was born in Badajoz, Spain, in 1957. He studied at the University of Extremadura, getting the B.Sc. degree in Electrical Engineering in 1982, and M.Sc. degree in Physics in 1995. He had got the Ph.D degree in 1998.

Since 1983, he is a lecturer at the Engineering School of the University of Extremadura. Currently, he holds the position of Professor in the area of Electrical Engineering.

In the field of research, he founded in 1999 the "Benito Mahedero" Group on Electrical Applications of Superconductors, which he is 